\title{
Emoção e soma (des)conectadas em páginas de revista: as categorias temáticas do discurso prescritivo sobre os fenômenos da vida e da doença
}

\author{
Emotion and soma (dis)connected in magazine pages: \\ the thematic categories of the prescriptive discourse \\ on phenomena of life and illness
}

Vera Lucia Pereira Alves

Daniela Dantas Lima ${ }^{1}$

Carlos Roberto Soares Freire de Rivorêdo ${ }^{2}$

Egberto Ribeiro Turato ${ }^{1}$

\footnotetext{
${ }^{1}$ Laboratório de Pesquisa Clínico-Qualitativa, Departamento de Psicologia Médica e Psiquiatria, Faculdade de Ciências Médicas, Universidade Estadual de Campinas. Campus Universitario Zeferino Vaz SN, Cidade Universitaria. 13083-970 Campinas SP. vera@alves.com.br ${ }^{2}$ Departamento de Pediatria, Faculdade de Ciências Médicas, Universidade Estadual de Campinas.
}

\begin{abstract}
Magazines sold on newsstands have become self-help texts, and the study of the topics covered makes it possible to understand how the discourses are constructed, how they become repositories used to give meaning to life. In the case of magazines that deal with the sphere of health, prescribing methods of treatment, prevention and even healthy lifestyles, the studies allow us to understand the meanings of discourses about body and health. In some articles, the emphasis that sometimes highlights the physical aspect is accompanied by the inclusion of mental aspects. This fact gave rise to this study, which seeks to clarify how this mind-body connection is conceptualized and prescribed in these pages. Six articles of a Brazilian health magazine published between August 2005 and February 2006 were analyzed regarding the content of the texts as well as graphic and textual features. The way this media format operates was considered significant, and when associated with the themes: selfdiagnosis, the place of emotion, the prescriptions and causality reinforce healthy lifestyles. Readers must learn to self-diagnose and control their emotions, considered to be juxtaposed to the physical emotions. The articles outline a field of health in which the mind-body split deepens and extends, establishing the medicalization of society.
\end{abstract}

Key words Psychosomatics, Media, Culture, Emotions
Resumo As revistas vendidas nas bancas têm se tornado textos de autoajuda e o estudo de suas matérias possibilita compreender como seus discursos são construídos, como se tornam repertórios utilizados para dar sentido à vida. No caso das revistas que versam sobre a esfera da saúde, que prescrevem receitas de tratamento, prevenção e até estilos de vida saudáveis, os estudos permitem compreender os significados dos discursos sobre corpo e saúde. Em algumas matérias, por vezes o destaque dado ao físico se faz acompanhar da inserção de aspectos mentais. Tal fato originou $o$ presente estudo que tem por objetivo clarificar como esta conexão mente e corpo é conceituada e prescrita nessas páginas. Seis matérias de uma revista brasileira de saúde, publicadas entre agosto de 2005 e fevereiro de 2006, foram analisadas quanto ao conteúdo dos textos e ao destaque gráfico e textual. Considerou-se significativo o formato em que esta mídia opera, pois associado às categorias temáticas: autodiagnóstico, o lugar das emoções, as prescrições e a causalidade reforça estilos de vida saudáveis. Para tanto o leitor deve aprender a se autodiagnosticar e controlar suas emoções, consideradas contrapostas ao físico. As matérias delineiam um campo de saúde em que a cisão mente corpo se adensa e se prolonga, instaurando a medicalização da sociedade.

Palavras-chave Psicossomática, Mídia, Cultura, Emoções 


\section{Introdução}

No decorrer de um estudo sobre literatura de autoajuda constatou-se que os magazines vendidos semanal e mensalmente nas bancas de revistas têm se tornado, eles próprios, textos de autoajuda, popularizando ainda mais este estilo literário, devido, entre outras coisas, ao preço menor em relação aos livros.

A revista une entretenimento e educação, fornecendo informações específicas àqueles que não podem ou não querem recorrer aos livros. São informações menos no sentido clássico e mais no sentido pessoal, uma vez que visam auxiliar o leitor em sua vida cotidiana. Talvez sejam também, muito procuradas pelo seu estatuto de verdade historicamente, o que é impresso parece mais verdadeiro do que aquilo que não o é. A venda anual brasileira de revistas de todos os tipos gira em torno de 600 milhões de exemplares ${ }^{1}$.

A esfera de conhecimentos que provavelmente mais interessa à atual sociedade é a da saúde. Dita como utopia e projeto de caráter universal no século XXI, a saúde se faz presente nas páginas de revistas que visam uma "verdadeira caça à saúde" ${ }^{\text {" }}$ Sua inserção no discurso jornalístico, que tem, pelo seu estatuto de verdade uma função disciplinadora, fortalece também seu caráter disciplinador $^{3}$. Prescrevem-se receitas de tratamento, prevenção e estilos de vida saudáveis. O corpo e seu cuidado, por estética ou por saúde, foram tema central e específico de algumas publicações (revistas semanais e femininas, por exemplo) até que se tornou, ele próprio, a razão de ser de algumas revistas, surgidas na década de $1980^{1}$.

O estudo desta mídia específica possibilita compreender como seus discursos são construídos, como se tornam repertórios utilizados para dar sentido à vida. Seu poder de transformação considerado ainda pouco estudado ${ }^{4}$ se faz já presente em alguns estudos, porém não de forma a destrinchar meandros do conceito de saúde em questão ${ }^{2,3,5,6}$. As revistas dão destaque ao físico e, por vezes, produzem matérias que visam maior abrangência do conceito, inserindo também o mental. Assim, de toda esta produção literária, optou-se por estudar as matérias de revistas que enfocassem patologias conjugando aspectos físicos e mentais. A intenção foi a de clarificar como esta conexão seria abordada, conceituada e prescrita.

\section{Método}

Foram analisadas seis matérias da revista brasileira de saúde - Viva Saúde - publicadas entre agosto de 2005 e fevereiro de 2006, acessadas nas páginas de Internet da própria revista.

A revista Viva Saúde é uma publicação da Editora Escala, situada no grupo de revistas: Vida Saudável. As matérias foram selecionadas em virtude de configurarem textos que na abordagem das patologias presentificam a conexão entre sintomas físicos e emocionais. Abordam a relação entre corpo e mente para o estabelecimento, tratamento e prevenção de doenças. A revista foi escolhida para o estudo porque também se identifica exatamente como veículo de imprensa que aborda tanto saúde física como emocional: "É a revista certa para homens e mulheres que se preocupam com a saúde do corpo e da mente"7.

Realizou-se a análise dos textos baseando-se na Análise de Conteúdo de Bardin ${ }^{8}$. Buscou-se destacar, de cada uma das matérias, as unidades de registro que delineavam os indicativos de como o tema era apresentado e concebido. Num segundo momento, agruparam-se os mesmos indicativos de todas as matérias, de modo a se construírem categorias temáticas indicativas da compreensão da conexão físico-emocional nestas publicações.

\section{Resultados e discussão}

Os temas abordados pelos artigos são: fibromialgia; ansiedade; depressão; estresse; isolamento social de idosos e a consequente aparição de doenças físicas e emocionais, e doenças que geram problemas emocionais (como mostra o Quadro 1). Não só os temas abordados - o conteúdo das matérias propriamente dito - mas também a configuração dada a estes textos foram analisados e discutidos. Deu-se início com esta última de modo que se possa compreender que o formato em que opera esta mídia, já é ele próprio significativo em relação ao tema.

Os assuntos são abordados com uma configuração bem peculiar, tanto gráfica quanto textual que, além de apontadas como de uso típico das revistas ${ }^{1}$, delineiam implícita e explicitamente sua intenção pedagógica. Mesmo que se considerem também outras mídias, outros produtos da cultura popular, como "pedagogias culturais"5 é a revista, dentre os veículos impressos, que objetiva uma complementação da educação e um aprofundamento de assuntos segmentados ${ }^{1}$. 
Quadro 1. Referência das Matérias Analisadas - Revista Viva Saúde.

\begin{tabular}{|l|c|l|}
\hline \multicolumn{1}{|c|}{ Título } & Tema & \multicolumn{1}{c|}{ Edição/Data } \\
\hline Ai como dói! & Fibromialgia & Edição 19, novembro de 2005 \\
\hline Alta ansiedade & Ansiedade & Edição 18, outubro de 2005 ${ }^{10}$. \\
\hline $\begin{array}{l}\text { Depressão: O quadro visto sob um } \\
\text { novo olhar }\end{array}$ & Depressão & Edição 16, agosto de $2005^{11}$. \\
\hline Para combater o estresse & Estresse & Edição 21, janeiro de 2006 ${ }^{12}$. \\
\hline Que solidão que nada... & $\begin{array}{c}\text { Isolamento social de idosos e e } \\
\text { doenças físicas e emocionais. }\end{array}$ & Edição 22, fevereiro de 2006 \\
\hline Sindrome do Intestino Irritável (S.I.I.) & $\begin{array}{c}\text { Doenças que geram problemas } \\
\text { emocionais }\end{array}$ & Edição 22, fevereiro de 2006 \\
\hline
\end{tabular}

O destaque gráfico, usual nesta mídia impressa, se não proposital, isto é, ideologicamente configurado para tal, finda por marcar a percepção do leitor. As explicações sobre as doenças, a sintomatologia, as prescrições dos autores e/ou profissionais entrevistados e as narrativas de pacientes têm uma impressão diferenciada do restante do texto, de forma que o leitor, mesmo não lendo toda a matéria, possa ter contato com os aspectos considerados centrais ao tema, o que, deste modo potencializa as mensagens intencionadas ${ }^{15}$. São quadros coloridos onde se imprimem a relação de sintomas da patologia; gráficos explicativos de áreas do corpo atingidas; fotomontagens (como por exemplo, a de um pé pisando em pregos, no artigo Ai como dói! $)^{9}$; fotos de pessoas numa sequência de recuperação da doença (na matéria sobre depressão, uma primeira foto mostra uma mulher cabisbaixa, depois entristecida e na última foto ela se encontra de pé, sorrindo).

As narrativas de entrevistados constituem o segundo elemento da configuração gráfico-textual das matérias, a ser analisado que, via de regra, também recebe destaque gráfico. $\mathrm{O}$ uso de texto com voz na primeira pessoa porta uma intimidade quando o narrador se abre para compartilhar confidências, como as de um amigo ${ }^{16}$ : por causa das inesperadas diarreias, a doença atrapalhou minha vida social (S.I.I. ${ }^{14}$. Desta maneira, o discurso de supostos portadores da patologia em questão parece cumprir o papel de ênfase ou alerta ao leitor, pela via da intimidade com ele estabelecida, intimidade esta também utilizada diretamente pelos autores e apontada como típica do veículo, pelos estudiosos de revistas ${ }^{1}$.
Outro elemento a configurar estas matérias e de uso recorrente é a citação de pesquisas científicas. Muitas vezes, estas surgem sem qualquer referência e fornecem dados vagos: Pesquisas mostram que algumas pessoas têm tendência genética... (Ai como dói!) $)^{9}$ e em outros momentos portam apenas dados epidemiológicos: $50 \% \mathrm{da}$ população têm ansiedade como refere o artigo Alta ansiedade ${ }^{10}$. O recurso a um instrumento científico e acadêmico ocorre com grande frequência. Todavia, estas revistas não são um veículo que divulga resultados de pesquisas cientificas e sim uma mídia que populariza a ciência ao veicular questões a ela relacionadas e que, anteriormente, só eram publicadas em revistas científicas. Operam, assim, um fenômeno denominado por "divulgação científica",617-19. Tal conduta mostra e reafirma a própria vocação destas revistas que, cumprindo a função de educar, intencionam ser uma ponte entre ciência e cultura ${ }^{1}$.

Divulgação cientifica, enquanto termo não se refere a um tipo de texto específico, mas relaciona-se à forma como se produz, formula e circula na sociedade o conhecimento científico ${ }^{19}$. Como prática, tem sido protagonizada por comunicadores e cientistas que, com textos próprios e disponibilidade de recursos da mídia objetivam que o patrimônio científico de especialistas alcance o público leigo. Quatro matérias do conjunto de textos analisados ${ }^{9-12}$ refletem exatamente esta prática, pois parecem ter sido elaboradas na sequência do lançamento de livros escritos por médicos que foram entrevistados para a matéria em questão ${ }^{9,12}$.

O recurso a entrevistados, frequente nestas publicações, parece parte de sua própria filosofia 
que considera o jornalista um profissional sem a especialização sobre os temas que escreve, mas capacitado a perguntar para os que os dominam a fim de que possa traduzir a informação aos leigos. Sendo assim, os especialistas, são entrevistados em algumas matérias e, às vezes, há mais de um médico consultado, e/ou vários profissionais, especialistas na patologia em questão. A matéria sobre depressão, por exemplo, conta com os esclarecimentos de um psiquiatra, um fisioterapeuta e um acupunturista.

Neste papel de divulgadora científica, a revista Viva Saúde se inscreve, assinalando ter por filosofia todos os elementos aqui descritos: A cada edição apresenta novidades sobre prevenção e tratamentos médicos, pesquisas na área de nutrição, terapias complementares, beleza e atividade física. Com uma equipe de colaboradores formada pelos melhores pesquisadores, professores e especialistas na área de saúde, Viva Saúde interpreta essa ciência de uma maneira simples e acessivel e, por isso, tornou-se um verdadeiro guia de bem estar e qualidade de vida para toda a família ${ }^{7}$.

A publicação evidencia-se pertencendo a uma sociedade direcionada pelos princípios científicos, baseada cada vez mais em sistemas de conhecimentos crescentemente desenvolvidos, estimuladora de uma compreensão mediada que o indivíduo deve ter de si e do mundo. Mediada, por "sistemas de especialistas"20,21 que possibilitam que tanto coisas como pessoas passem a ser apreendidos pela via da cientificidade, da qual o indivíduo retiraria sua maneira de pensar e de ser ou no caso destas matérias, sua maneira de cuidar de si, de sua saúde e de sua vida.

A saúde torna-se, assim, um imperativo nesta mídia impressa que pode atuar como mercantilizadora da doença: quando dificuldades se tornam disfunções que, por sua vez, se tornam doenças ${ }^{22}$; incentivadora de uma verdadeira "caça à saúde" ${ }^{2}$, na busca infinita pela prevenção e preconizadora de estilos de vida saudáveis ${ }^{23}$.

Preconizar, manter, buscar estilos saudáveis de vida são práticas que decorrem aqui de prescrições bem específicas, como se evidencia pela análise do conteúdo destes textos nas categorias: autodiagnóstico, o lugar das emoções, prescrições e causalidade.

\section{As categorias temáticas do discurso prescritivo sobre os fenômenos da vida e da doença}

As matérias se apresentam como textos cuja principal função é instrumentalizar o leitor no seu autodiagnóstico. Esta função é compreendida pelo recurso dos autores à explicitação detalhada dos sintomas da doença em questão; pelo recurso às narrativas de pacientes da mesma; pelas explicações de profissionais entrevistados e pela disposição de todos estes elementos em quadros destacados ou no formato check list precedidos de frases como: saiba como identificar e enfrentar este distúrbio difícil de ser diagnosticado [...] pânico, sufoco, desespero [...] Estas são algumas das sensações comuns do dia a dia de quem sofre de $\mathrm{SII}^{14}$. Além do uso de testes (presença de parte do Inventário de depressão de Beck em uma das matérias). O pressuposto básico é o de que a informação é valorosa para o autodiagnóstico: $c o-$ nhecer sintomas é o melhor para cuidar da saúde (Ai como dói!) ${ }^{9}$.

$\mathrm{Na}$ tentativa de apresentar as patologias numa conexão mente-corpo, emoções e soma, uma segunda categoria temática se evidencia aqui sendo nomeada de o lugar das emoções. Este é um lugar, bastante peculiar, que contrapõe as duas esferas: emoção e orgânico. Os aspectos subjetivos e emocionais são ditos como do imaginário em oposição ao real, físico: Suas dores eram reais, sim, e não fruto de sua imaginação, nem uma maneira de querer chamar a atenção (Ai como dói $)^{9}$. Em cinco dos seis artigos encontra-se tal oposição que, por vezes, tenta ressalvar que uma doença psicossomática tem "males físicos [que] não são falsos" (Que solidão que nada) ${ }^{13}$. Doenças psicossomáticas para os autores destas matérias são a asma, a hipertensão e as dermatites em geral ${ }^{13}$. A designação de uma doença como tal tem por referência um prejuízo orgânico de causa ou influência emocional: Doenças psicossomáticas, ou seja, males físicos (como hipertensão, asma, dermatites) que podem estar ligados a sentimentos como medo, angústia, tristeza (Que solidão que nada ${ }^{13}$. Assim sendo, os textos, tentando sair da ideia de que o emocional é "falso", ainda reificam a noção clássica de psicogênese em detrimento de uma visão de corpo e mente integrados, que parece realmente impossível para estas matérias, uma vez que evidenciam, por meio de recurso linguístico a oposição e não a conexão mente-corpo. Com o uso da preposição de limite - até - os autores que intencionam uma ligação entre mente e corpo, tratam estas duas dimensões de forma separada. A preposição dá ênfase ou à emoção ou ao físico quando se aborda ou quando se pretende delinear a seriedade da patologia em questão. Quando a doença em questão é física, o até aponta as possíveis consequências emocionais, caso esta não tenha sido corre- 
tamente diagnosticada. O mesmo se dá quando se trata de problemas emocionais, sendo as consequências, até físicas.

As emoções, mesmo quando não apontadas como contrapostas ao físico, são elementos nefastos que precisam ser absolutamente controladas: Em vez de se emocionar e se envolver com a história de um filme, por exemplo, procure observá-la e analisá-la no controle das emoções (Para combater o estresse $)^{12}$. O mesmo estilo de conselho alcança também a esfera das relações pessoais, preconizando o não envolvimento: $a$ compreensão de uma pessoa que não se deixa envolver completamente pelos problemas dos outros é ainda melhor (Para combater o estresse) ${ }^{12}$. As emoções são remetidas a um lugar outro que não a possibilidade de sua expressão. O descontrole é, por exemplo, sinônimo ou causa de estresse: $o$ indivíduo acaba desencadeando sentimentos negativos e emoções explosivas, causando o estresse (Para combater o estresse) $)^{12}$.

A postura racional que o leitor deve criar para si nesta aprendizagem está imbuída da crença de que pode e deve comandar sua mente: olhe para a dificuldade, procure entendê-la, aumente suas informações e seu conhecimento sobre ela [...] se não for possível encará-la, tente não pensar neladistraia a mente com outra coisa e até 'brigue' com sua cabeça se for preciso (Alta ansiedade) ${ }^{10}$. Trata-se de uma proposta de autocontrole que, por vezes, se apresenta de forma ambígua ou disfarçada. Na mesma matéria, linhas após a citação acima, encontra-se uma prescrição contraditória: abra mão da prepotência de seu cérebro e entenda que não somos superpoderosos, que tudo possuímos o poder para controlar (Alta ansiedade) ${ }^{10}$.

No complemento desta concepção de emoção, a possibilidade de psicoterapia, um dos conselhos que compõem a categoria prescrições, só poderia mesmo se referir à aprendizagem do controle de emoções, o que é, por sua vez, compatível com o destaque dado à abordagem cognitivo-comportamental. A menção à psicoterapia ou ao auxílio proveniente da esfera da psicologia que se segue ao debate acerca das emoções citado acima, aponta a psicoterapia como tratamento complementar, igualado à ioga ou ao relaxamento (Depressão: o quadro visto sob um novo olhar $)^{11}$. Ela ainda se encontra igualada a um processo de aprendizagem: O psicólogo e o psiquiatra têm um papel importante no tratamento da S.I.I.. Com a terapia o indivíduo aprende a controlar a angustia e o estresse (S.I.I.) ${ }^{14}$.

As outras prescrições que compõem as matérias passam pela sugestão de tratamentos al- ternativos e complementares, como acupuntura, ioga, hidroginástica, caminhada, dietas, massagens. Os medicamentos não são prescritos, são, porém, apontados como existentes e às vezes indispensáveis: A maioria dos profissionais também não dispensa o uso de antidepressivos no tratamento (matéria sobre fibromialgia) ${ }^{9}$. No entanto, medicamentos sem restrição, como fibras sintéticas, não são apenas sugeridos como descritos, assinalando-se o laboratório que os produz: Quanto aos medicamentos, um dos avanços é a fibra sintética policarbofila cálcica, recém-lançada pela LIbbs Farmacêutica (S.I.I. $)^{14}$. Entretanto, impera a prescrição para que seja ele, o leitor, o indivíduo que busque em si próprio as forças para curar-se: É necessário querer mudar é uma das prescrições da matéria sobre ansiedade que indica com destaque gráfico o autocontrole: mente acelerada é mente desequilibrada. Para livrar-se da ansiedade, é preciso aprender a escapar de seu dominio ${ }^{10}$.

A tentativa de conexão corpo mente se faz presente também nas considerações sobre a causalidade das patologias, outra categoria temática deste estudo que, na matéria sobre Síndrome do Intestino Irritável (S.I.I.) ${ }^{14}$ aponta a doença como consequência de causas multifatoriais, ao mesmo tempo em que faz desaparecer dentre elas a causa psicológica: É fundamental salientar que se trata de um distúrbio médico real de causas multifatoriais, e não uma reação nervosa imaginária ao estresse e à sobrecarga psicológica cotidiana (S.I. I) ${ }^{14}$.

A matéria sobre fibromialgia apresenta a patologia como não decorrendo de causa psicológica: Os especialistas acreditam que sua origem está em uma alteração no mecanismo de controle da percepção e modulação da dor [...]. Nas pessoas que sofrem de fibromialgia parece existir um defeito neste mecanismo de dor?.

Este fenômeno parece espelhar uma mesma e típica postura da medicina, como registrada por Camargo Júnior ${ }^{24}$. Segundo o autor, a busca pela causa das doenças, essencial à medicina, acaba por produzir uma identificação entre doença e lesão que, em síntese, reduz ao biológico todo o processo de adoecimento. Aspectos como os psicológicos e sociais são excluídos, mesmo quando da ideia de multicausalidade, pois estas acabam resumidas num conjunto de causas igualadas entre si na produção das doenças, resultando, por fim, numa unicausalidade que "achata perspectivas e apaga diferenças"24.

Operando desta maneira, as matérias prescrevem ao leitor um "correto" autodiagnóstico, seguido de um "correto" comportamento de au- 
tocontrole. Cumprem, assim, o papel da mídia identificada com a racionalidade, a tecnologia, o prazer e a preocupação com os sentimentos. Preconizam que as emoções sejam contidas, reservadas para momentos convenientes, quando expressas sem risco para a vida cotidiana ou, neste caso, para a saúde. Caminha-se aqui para uma sociedade da cultura popular ininterrupta, que induz, a pedido, sentimentos de pouco prejuízo ${ }^{25}$.

Operacionaliza-se todo um processo centrado na capacidade de racionalidade dos indivíduos. A eles se pede que se distanciem de si para analisar, compreender e controlar seus atos, baseando-se para tanto, cada vez mais em sistemas de conhecimentos crescentemente desenvolvidos e divulgados em nossa sociedade, como o fazem estas próprias publicações.

O conhecimento e a informação são vistos como detentores do poder de alteração da vivência daqueles que a ele têm acesso, como expresso em um dos artigos: $O$ melhor 'raio x' para o diagnóstico é o conhecimento dos sintomas da síndrome (Ai como dói) ${ }^{9}$

\section{Considerações finais}

Canguilhem ${ }^{26}$, na década de 1960, dizia ser uma "realidade incontestável" que a existência da medicina se deva ao fato de haver homens que se sentem doentes e não por existirem médicos a informá-los de sua doença. Atualmente, porém, mais que a própria medicina, a posição de informante das doenças é ocupada cada vez mais pela mídia impressa: literatura de autoajuda; revistas populares; jornais; além da TV, internet e rádio. Vivemos um momento em que a divulgação cientifica é predominante em nossa sociedade e tem uma função compreendida como a de processos que passam a fazer parte do imaginário social de nossa realidade, como a arte, por exemplo ${ }^{6}$.

Orientar as pessoas a em que e em como pensar, sentir e agir parece estar sendo a função da mídia. Trata-se, de "um equipamento social"27 para significar e interpretar o mundo, falando pelo e para o individuo, preconizando, no caso destas matérias, um estilo de vida saudável ${ }^{23}$ que tais textos ressaltam como aquele em que as emoções contrapostas ao físico devem ser controladas, dominadas pela capacidade de racionalização dos indivíduos. Delineiam, assim, um campo de saúde concebido de forma em que a cisão mente corpo se adensa e se prolonga a uma segunda, separando, nos aspectos mentais, emoção e cognição, colocando-se desta forma, mais além da cisão mente corpo, no entanto, aquém da unidade.

A trajetória apresentada pode apontar para outro aspecto, o da medicalização da sociedade que essas publicações parecem aprofundar. Medicalização compreendida como Foucault a definiu no Nascimento da Clínica ${ }^{28}$, não apenas como preocupar-se com o bem estar do corpo, mas que ele (o corpo) é medicamente instituído. Para além disso, a vida passa a ser medicamente instrumentalizada. Fica impossível pensar a vida sem o médico e a medicina. Todavia, o traço mais importante dessa medicalização da sociedade é a sua disseminação pela textura social. Ora, se a medicina moderna é forjada no fogo da separação mente e corpo, e os artigos afirmam isto, reafirma-se a medicalização da sociedade e dos sujeitos da qual o corpo se torna objeto, subsumindo não a mente, mas a integração entre as duas dimensões. Tal análise carece de uma outra investigação ...

\section{Colaboradores}

VLP Alves é responsável pela concepção, delineamento, análise dos dados, redação do artigo e revisão crítica. DD Lima colaborou na análise dos dados, na redação do artigo e na revisão crítica. ER Turato e CRSF de Rivorêdo colaboraram na revisão crítica. 


\section{Referências}

1. Scalzo M. Jornalismo de revista. São Paulo: Contexto; 2008.

2. Sudo N, Luz MT. O gordo em pauta: representações do ser gordo em revistas semanais. Cien Saude Colet 2007; 12(4):1033-1040.

3. Castro A. "O melhor da vida" - discursos de promoção de saúde na mídia impressa da Cidade do Rio de Janeiro [dissertação]. Rio de Janeiro: Fiocruz, Ensp; 2004.

4. Spink MJP, Medrado B, Mello RP. Perigo, probabilidade e oportunidade: a linguagem dos riscos na mídia. Psicol. Reflex. Crit. 2002; 15(1):151-164 .

5. Louro G. Gênero: questões para a educação. In: Bruschini C, Umbehaum S, organizadores. Gênero, democracia e sociedade brasileira. São Paulo: FCC, Editora 34; 2002. p. 225-242.

6. Vogt CA. Cultura científica: Desafios. São Paulo: Edusp; 2006.

7. Conheça a revista. Viva Saúde [online] [acessado 2011 jun 20]. Disponível em: http://revistavivasaude .uol.com.br/prevencao-medicina/fixos/conheca-arevista.asp

8. Bardin L. Análise de conteúdo. Lisboa: Edições 70; 1977.

9. Ai, como dói. Viva Saúde 2005; nov. [cerca de 10 p.]. [acessado $2012 \mathrm{dez} 3$ ]. Disponível em: http:// revistavivasaude.uol.com.br/edicoes/19/artigo 12122-1.asp?o=r

10. Alta Ansiedade. Viva Saúde 2005; out. [cerca de 10 p.]. [acessado $2012 \mathrm{dez} 3$ ]. Disponível em: http:// revistavivasaude.uol.com.br/edicoes/18/artigo 11193-1.asp

11. Depressão: O quadro visto sob um novo olhar. Viva Saúde 2005; ago [cerca de 10 p.]. [acessado 2012 dez 3]. Disponível em: http://revistavivasaude.uol. com.br/edicoes/16/artigo9972-1.asp?o=r

12. Para combater estresse. Viva Saúde 2006; jan. [cerca de 10 p.]. [acessado $2012 \mathrm{dez} 3$ ]. Disponível em: http://revistavivasaude.uol.com.br/edicoes/21/artigo 13832-1.asp?o=r

13. Que solidão, que nada... Viva Saúde 2006; fev. [cerca de 10 p.]. Disponível em: http://revistavivasaude. uol.com.br/edicoes/22/artigo 14864-1.asp?o=r

14. Síndrome do Intestino Irritável. Viva Saúde 2006; fev. [cerca de 10 p.]. [acessado 2012 dez 3]. Disponível em: http://revistavivasaude.uol.com.br/edicoes/ 22/artigo14864-2.asp
15. Spink MJP, Galindo D, Ribeiro RN, Ornellas MA. Sobre palavras que vendem coisas: o glossário do risco em anúncios de revistas. Estud. psicol. (Natal) 2007; 12(1):13-21.

16. Gay P. A experiência burguesa da rainha vitória a freud: o coração desvelado. São Paulo: Companhia das Letras; 1999.

17. Bertolli CF. A divulgação científica na mídia impressa: as ciências biológicas em foco. Ciênc. Educ. 2007; 13(3):351-368.

18. Mora A. A divulgação da ciência como literatura. Rio de Janeiro: Casa da Ciência; 2003.

19. Silva H. O que é divulgação científica? Ciência \& Ensino 2006; 1(1):53-59.

20. Beck U, Giddens A, Lasch S. Modernização Reflexiva: Política, tradição e estética na ordem social moderna. São Paulo: Editora da UNESP; 1997.

21. Giddens A. A Transformação da Intimidade: Sexualidade, Amor e Erotismo nas Sociedades Modernas. São Paulo: Editora da UNESP; 1993.

22. Moynihan R. The making of a disease: female sexual dysfunction. BMJ 2003; 326(7379):45-47.

23. Fitzgerald F. The tyranny of health. $N$ Engl J Med 1994; 331(1):1660-1661.

24. Camargo Júnior KR. Biomedicina, saber \& ciência: uma abordagem crítica. São Paulo: Hucitec; 2003.

25. Glitin T. Mídias sem limite. Rio de Janeiro: Civilização Brasileira; 2003

26. Canguilhem G. O normal e o patológico. Rio de Janeiro: Forense; 2007.

27. Coimbra C. A mídia e produção de modos de existência. Psic: Teor e Pesq 2001; 17(1):1-4.

28. Foucault M. O nascimento da clínica. Rio de Janeiro: Forense; 2006

Artigo apresentado em 01/09/2011

Aprovado em 18/03/2012

Versão final aprovada em 15/04/2012 